\title{
Travayda Duş Almanın Doğum Memnuniyetine ve Doğum Sonrası Konforuna Etkisi
}

\section{The Effect of Taking a Shower in Labor on the Birth Satisfaction and Postnatal Comfort}

\author{
Sümeyra TOSUN ${ }^{I}$ Ayşe TAŞTEKIN OUYABA ${ }^{2}$
}

\section{$\underline{\mathrm{OZZ}}$}

Amaç: Bu çalışmanın amacı travayda duş almanın doğum memnuniyetine ve doğum sonrası konforuna etkisini araştırmaktır.

Araçlar ve Yöntem: Çalışmada randomize kontrollü çalışma modeli kullanılmıştır. Doğumun aktif fazında bulunan gebeler rastgele 1:1 oranında deney ve kontrol gruplarına $(50+50)$ ayrılmıştır. Veriler doğum öncesi ve doğum sonrası olmak üzere iki kez toplanmıştır. Doğum öncesinde veriler, Doğum Öncesi Veri Toplama Formu ile toplanmıştır. Doğumdan sonra veriler doğum, yeni doğan ve doğum sonrası döneme ait sekiz sorudan oluşan Doğum Sonrası Veri Toplama Formu, Doğum Sonrası Konfor Ölçeği ve Doğum Memnuniyet Ölçeği ile toplanmıştır. Deney grubundaki gebeler, travay odalarında bulunan banyolarda, en az 20 dakika $37^{\circ} \mathrm{C}$ sıcaklıktaki su ile duş aldırılmıştır. Verilerin değerlendirilmesinde Student t, Mann Whitney U ve ki-kare testleri kullanılmıştır.

Bulgular: Grupların doğum memnuniyeti ve doğum sonu konfor ölçek puanları arasında anlamlı bir farklılık bulunmamıştır (p>0.05). Deney grubunda doğum memnuniyeti ve doğum sonu konforu arasında pozitif yönde kuvvetli bir ilișki vardır ( $\mathrm{r}=0.68)$. Deney grubunda epizyotomi yapılmayan ve ilk yarım saatte bebeğini emziren kadınların doğum sonu konfor ve memnuniyet puanları anlamlı düzeyde daha yüksek bulunmuştur $(\mathrm{p}<0.05)$. Epizyotomi varlığına ve ilk emzirmeye başlama zamanına göre grupların doğum sonu konfor ve memnuniyet düzeyleri arasında bir fark yoktur ( $>>0.05)$.

Sonuç: Travayda duş almanın doğum memnuniyeti ve doğum sonu konforu üzerine direkt bir etkisi olmasa da, doğum sonuçlarını olumlu yönde etkileyebileceği belirlenmiştir.

Anahtar Kelimeler: doğum; doğum memnuniyeti; doğum sonrası konforu; hidroterapi.

\section{ABSTRACT}

Purpose: This study aimed to investigate the effect of showering in labor on the birth satisfaction and maternal postnatal comfort of the mother.

Materials and Methods: Randomized controlled study model was used in the study. Pregnant women in the active phase of labor were randomly divided into 1:1 experimental and control groups (50+50). The data were collected twice, before and after birth, using the questionnaire form. Prenatal data was collected using the Prenatal Data Collection Form. Data after birth was collected with the Postnatal Data Collection Form, Postnatal Comfort Scale, and Birth Satisfaction Scale. The pregnant women in the experimental group were showered in $37^{\circ} \mathrm{C}$ water for at least 20 minutes. Student t, Mann Whitney U, and chi-square tests were used to evaluate the data.

Results: There was no significant difference between the birth satisfaction and postpartum comfort scale scores of the groups (p $>0.05$ ). There was a strong relationship between birth satisfaction and postpartum comfort in the experimental group ( $\mathrm{r}=0.68)$. In the experimental group, postpartum comfort and satisfaction scores were significantly higher in women who did not undergo episiotomy and breastfeed in the first half-hour $(\mathrm{p}<0.05)$. There was no difference between postpartum comfort and satisfaction levels of the groups according to the presence of episiotomy and the time of first breastfeeding $(\mathrm{p}>0.05)$.

Conclusion: Although showering in labor did not have a direct effect on birth satisfaction and postpartum comfort, it was found that it can positively affect birth results.

Keywords: labor; birth satisfaction; postpartum comfort; hydrotherapy.

Gönderilme tarihi: 25.10.2020, Kabul edilme tarihi: 23.03.2021

${ }^{1}$ Uzman Hemşire, Afyonkarahisar Devlet Hastanesi Eğitim Birimi, Afyonkarahisar, Türkiye

${ }^{2}$ Dr. Öğretim üyesi, Afyonkarahisar Sağlık Bilimleri Üniversitesi, Sağlı Bilimleri Fakültesi, Hemşirelik Bölümü, Afyonkarahisar, Türkiye.

Sorumlu Yazar: Dr. Öğr. Üyesi Ayşe Taştekin Ouyaba, Afyonkarahisar Sağlık Bilimleri Üniversitesi, Sağlık Bilimleri Fakültesi, Hemşirelik Bölümü,

Afyonkarahisar, Türkiye. e-posta: ayse.tastekin@hotmail.com 


\section{GíRIŞ}

"Konfor" kavramı Latince "güçlendirmek" anlamına gelmektedir. ${ }^{1}$ Konfor; "ferahlama, huzura kavuşma ve sorunların üstesinden gelebilmek için temel insan gereksinimlerini karşılama deneyimidir". ${ }^{2}$ Konfor algısı, hasta memnuniyeti ve yaşam kalitesi üzerine etkilidir. ${ }^{3}$ Son yıllarda yapılan bir çalışmada, postpartum bakımın doğum sonu dönemde uyumu kolaylaştırdığı ve bireysel ihtiyaçları giderdiği belirlenmiştir. Doğum sonrası konforu değerlendirmek, kadının gereksinimlerin giderilmesi açısından önemli bir ayrıntıdır. ${ }^{4}$

Son zamanlarda popülaritesi giderek artan doğumda hidroterapi uygulamalarında, süreci iyileştirmek, konforu artırmak ve gevşeme sağlamak amacıyla ılık sudan yararlanılmaktadır. Doğumda hidroterapi kullanımı, kan basıncını düşürür, ${ }^{5}$ uterus perfüzyonunu arttırır, doğum ağrıs1nın daha az hissedilmesini sağlar, oksitosin salınımı artırır, stres hormonlarının salınımını azaltır ${ }^{6}$ ve doğumda müdahale oranını azaltır. ${ }^{7}$ Doğumda hidroterapinin etkisinin değerlendirildiği çalışmalarda, çoğunlukla suya daldırma / suda doğum yönteminin kullanıldığı görülmektedir. ${ }^{8-10}$ Bununla birlikte doğumda duşun etkisini inceleyen çalışmalara odaklanan bir sistematik incelemede, duşun maternal, fetal veya neonatal hasara yol açmadığı, ağrıyı ve anksiyeteyi azalttığı rapor edilmiştir. ${ }^{8}$ Tuncay ve arkadaşlarının çalışmasında (2019), hidroterapi uygulanan nulliparlarda kontrol grubuna göre, doğum eyleminin aktif fazının ve ikinci evresinin daha kısa sürdüğü, üçüncü evresinin süresinin değişmediği belirlenmiştir. Ayrıca eylemin aktif fazında müdahale grubunun ağrı skorları daha düşük, yenidoğanlarının 1. ve 5. dakikalardaki Apgar skorların daha yüksek olduğu tespit edilmiştir. ${ }^{10}$ Mollamahmutoğlu ve arkadaşlarının çalışmasında (2012) suda doğum yapan grubun ağrı skorlarlarının daha düşük olduğu, doğum eyleminin ikinci ve üçüncü evresinin süresinin kısaldığı, indüksiyon ve epizyotomiye daha az ihtiyaç duyulduğu, ancak perineal laserasyon riskinin arttıdığı tespit edilmiştir. Doğumu çeşitli şekillerde destekleyen hidroterapi uygulaması ile ilgili daha fazla araştırma yapılması önerilmektedir. ${ }^{10}$ Günümüzde giderek daha ilgi duyulan bir konu olan hidroterapinin doğumda etkisi ile ilgili Türkiye'de yapılan ça- lışmaların sayısı oldukça sınırlı sayıdadır. ${ }^{9,10}$ Bu çalışmanın amacı, travayda duş almanın doğum memnuniyetine ve doğum sonrası konforuna etkisini değerlendirmektir.

\section{ARAÇLAR ve YÖNTEM}

\section{Örneklem}

Araştırmada deney-kontrol gruplu çalışma modeli kullanılmıştır. Bu çalışma, 800 yatak kapasiteli, anne ve bebek dostu olan Afyon Devlet Hastanesinin lohusa ve doğum cerrahisi servislerinde yatan kadınlarla, Haziran - Ekim 2017 tarihleri arasında yürütülmüştür. Araştırmada örneklem büyüklügünü hesaplamak için G-Power 3.1.9.2 programı ile güç analizi yapılmıştır. Bu çerçevede anlamlılık düzeyi (a) 0.05 , etki büyüklüğü (d) 0.6 , güç (p) 0.80 alınarak, her bir grup için örneklem büyüklüğü 36 olarak hesaplanmıştır. ${ }^{11}$ Çalışmaya 18-49 yaşlarındaki miyadında vajinal doğum yapan, okuma yazma bilen, iletişim problemi olmayan, eylemin aktif fazında bulunan (servikal açıklığı en az $5 \mathrm{~cm}$ olan), düzenli uterus kontraksiyonları ve fetal kalp atımları olan, herhangi bir sağlık sorunu bulunmayan, çalışmaya katılmayı kabul eden gebeler dâhil edilmiştir. Riskli gebeliği olanlar, sezaryen doğuma alınanlar, gebelik ve erken postpartum dönemde perinatal ölüm yaşayanlar, çalışmanın dâhil edilme kriterlerine uymayan ve çalışmaya katılmaya gönüllü olmayan gebeler çalışmadan dışlanmıştır.

Çalışma için 146 gebenin dâhil edilme kriterlerine uyduğu tespit edilmiştir. Çalışma başladıktan sonra farklı gerekçelerle 46 gebe çalışmadan dışlanmıştır. Çalışmanın dâhil edilme kriterlerine uyan travaydaki gebeler rastgele olacak şekilde 1/1 oranında deney ve kontrol gruplarına randomize edilmiştir. Araştırmanın dâhil edilme kriterlerine uyan ilk gebe deney grubuna, ikinci gebe kontrol grubuna alınmıştır. Bu şekilde seçim yapılarak tek sayılı sıradaki gebeler $(1,3,5,-, 95,97,99)$ deney grubuna; çift sayılı siradaki gebeler $(2,4,6,-, 96,98,100)$ kontrol grubuna alınmıştır (Şekil 1). Randomize edilen tüm gebeler istatistiksel analize dâhil edilmiştir (Intention-to-treat analysis). 


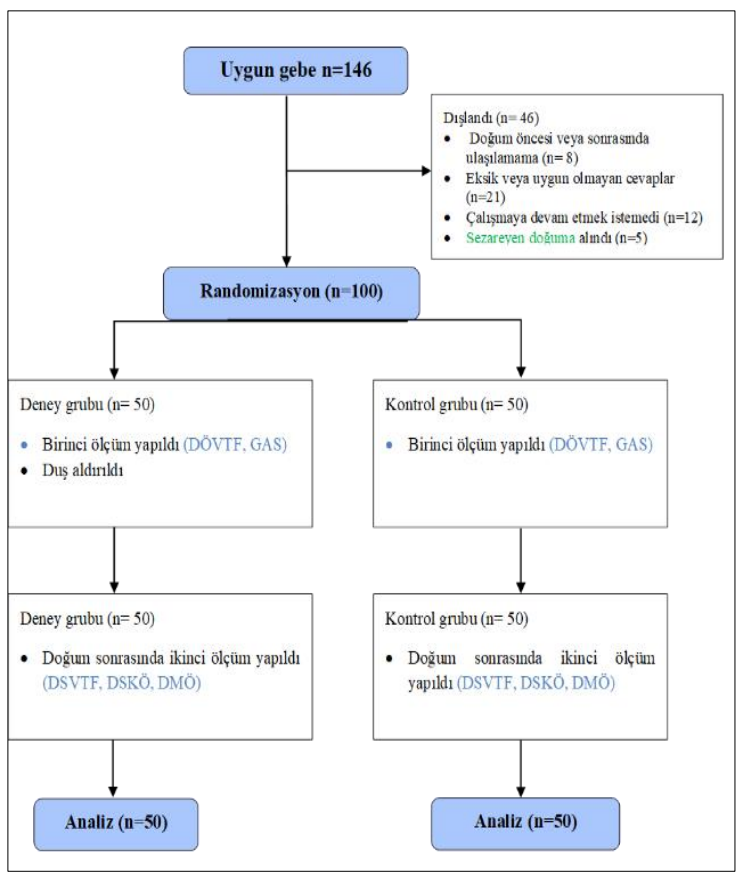

Şekil 1. Çalışmanın akış şeması

DÖVTF: Doğum Öncesi Veri Toplama Formu, GAS: Görsel Analog Skala, DSVTF: Doğum Sonrası Veri Toplama Formu, DSKÖ: Doğum Sonrası Konfor Ölçeği, DMÖ: Doğum memnuniyet Ölçeği.

Veriler birinci yazar tarafindan doğum öncesi ve doğum sonrası olmak üzere iki kez toplanmıştır. Doğum öncesinde veriler, Doğum Öncesi Veri Toplama Formu ile toplanmıştır. Doğum Öncesi Veri Toplama Formu gebelerin sosyodemografik bilgilerini, jinekolojik ve obstetrik öykülerini, vital bulgularını, $\mathrm{SPO}_{2}$ değerlerini, travayda duş almaya dair düşüncelerini ortaya çıkaran 30 sorudan oluşmaktadır. Ayrıca formda gebelerdeki ağrının şiddetini değerlendirmeye yarayan Görsel Analog Skala (GAS) kullanılmıştır. GAS, eylemin aktif fazında bir kez değerlendirilmiştir.

Doğumdan sonra veriler doğum, yeni doğan ve doğum sonrası döneme ait sekiz sorudan oluşan Doğum Sonrası Veri Toplama Formu, Doğum Sonrası Konfor Ölçeği (DSKÖ) ve Doğum Memnuniyet Ölçeği (DMÖ) yard1mıyla toplanmıştır. Doğum Sonrası Veri Toplama Formu ile yeni doğanın 1. ve 5. dakikadaki apgar skoru, kord PH'ı, epizyotomi varlığı, bebeğin ilk emzirildiği süre ve postpartum 1. günde vajinal kanama takibini içeren bilgiler toplanmıştır.

Doğum Sonrası Konfor Ölçeği, Karakaplan ve Yildiz (2010) tarafindan geliştirilmiş, doğum sonu konfor gereksinimlerin belirlenmesi ve değerlendirilmesinde kullanılan bir ölçektir. DSKÖ 34 maddeden ve üç faktörden oluşan, 5'li likert tipi bir ölçektir. Her bir madde için "tamamen katılıyorum 5" ve "kesinlikle katılmıorum 1" arasında değişen puanlama yapılmıştır. Bu doğrultuda ölçekten alınacak en düşük puan 34, en yüksek puan 170'dir. Puan yükseldikçe doğum sonu konfor algısının arttığı düşünülür. Orijinal ölçeğin Cronbach's Alpha değeri 0.78; ${ }^{12}$ bizim çalışmamızda 0.86 bulunmuştur.

Doğum Memnuniyet Ölçeği, Martin ve Fleming (2011) tarafından geliştirilmiş kadınların doğum memnuniyetine ilişkin algılarını değerlendirmek için geliştirilmiş bir ölçektir. ${ }^{13}$ Ölçek 5'li likert tipte olup, "Kesinlikle katıllyorum: 5" ve "Kesinlikle katılmıyorum: 1" arasında puanlanmaktadır. Ölçek 30 maddelik olup, ölçekten alınabilecek puan 30-150 puan arasında değişmektedir. Ölçekten alınan puan arttıkça doğum memnuniyeti artmaktadır. Ölçeğin Türkçe uyarlama çalışmasında Cronbach's Alpha katsayısı $0.62 ;^{14}$ bizim çalışmamızda 0.86 bulunmuştur.

\section{Araştırmanın Uygulanması}

Araştırmamıza dâhil edilen tüm gebelere öncelikle Doğum Öncesi Veri Toplama Formu uygulanmıştır. Deney grubundaki gebelere travay odalarında bulunan banyolarda en az $20 \mathrm{dk}$. süre ile $37^{\circ} \mathrm{C}$ sıcaklıkta suyun altında tüm vücudunu kapsayacak şekilde birinci araştırmacı tarafından duş aldırılmıştır. Deney grubundaki gebelere duş alma esnasında bir refakatçisinin eşlik etmesi sağlanmıştır. Doğum salonunda her gebenin odası farklı olduğundan, deney grubuna yapılan müdahaleden kontrol grubunun etkilenmesi önlenmiştir.

Kontrol grubundaki tüm gebelerde duş almanın önlenmesi adına gerekli önlemler alınmıştır. Kontrol grubunda araştırmacılardan habersiz duş alan gebe bulunmamaktadır.

\section{Verilerin Değerlendirilmesi}

Verilerin normal dağılıma uygunluğu Shapiro Wilk ile test edilmiştir. Normal dağılan değişenlerde iki bağımsız grup karşılaştırılmasında Student $\mathrm{t}$ test, normal dağılmayan özellikler için ise Mann Whitney U testileri, kategorik değişkenler arasındaki ilişkilerin test edilmesinde ki-kare testi kullanılmıştır. Ölçeklerin Cronbach's Alpha katsayısı hesaplanmıştır. İstatistiksel analizler SPSS $22^{15}$ yazıl1mında yapılmış, anlamlılık düzeyi $\mathrm{p}<0.05$ kabul edilmiştir. 
Çalışmanın yapılabilmesi için Afyon Kocatepe Üniversitesi Girişimsel Olmayan Klinik Araştırmalar Etik Kurulu'ndan (02.06.2017 tarih ve 2017/6-170 say11) ve Afyonkarahisar Devlet Hastanesi yönetiminden (26.09.2017 tarih ve 2017/19 numaralı) izin alınmıştır. Bu çalışma Helsinki Bildirgesi'nde yer alan ilkelere uygun olarak yürütülmüştür. Çalışmaya katılan gebelerin bilgilendirilmiş onamları alınmıştır.

\section{Kadınların Sosyodemografik, Jinekolojik, Obstetrik Özellikleri}

Çalışma kapsamına alınan kadınların sosyodemografik, jinekolojik ve obstetrik özellikleri karşılaştırıldığında, grupların homojenliği bakımından çalışma durumu dışındaki değişkenlerin tümünde fark olmadığı tespit edilmiştir (p>0.05; Tablo 1).

\section{BULGULAR}

Tablo 1. Kadınların Sosyodemografik, Jinekolojik ve Obstetrik Özellikleri.

\begin{tabular}{|c|c|c|c|c|c|}
\hline Değişkenler & & $\begin{array}{l}\text { Deney } \\
\bar{X} \pm \text { SS / n(\%) }\end{array}$ & $\begin{array}{l}\text { Kontrol } \\
\bar{X} \pm \mathrm{SS} / \mathrm{n}(\%)\end{array}$ & İstatistik & $\mathrm{p}$ \\
\hline Yaş & & $25.3 \pm 4.2$ & $24.1 \pm 5.1$ & $1.288^{*}$ & 0.201 \\
\hline Gebelik sayısı & & $1.9 \pm 0.9$ & $2.6 \pm 5.3$ & $-0.190^{* *}$ & 0.850 \\
\hline Yaşayan çocuk sayısı & & $0.8 \pm 0.9$ & $0.7 \pm 0.8$ & $0.573^{*}$ & 0.568 \\
\hline \multirow{4}{*}{ Eğitim durumu } & İlkokul & $6(0.12)$ & $11(0.22)$ & & \\
\hline & Ortaokul & $24(48)$ & $23(0.46)$ & $4.271^{* * *}$ & 0.371 \\
\hline & Lise & $10(0.20)$ & $10(0.20)$ & & \\
\hline & Üniversite & $10(0.20)$ & $6(0.12)$ & & \\
\hline \multirow{2}{*}{ Çalışma durumu } & Çalışıyor & $11(0.22)$ & $2(0.04)$ & $7.162^{* * *}$ & 0.007 \\
\hline & Çalışmıyor & $39(0.78)$ & $48(0.96)$ & & \\
\hline \multirow{2}{*}{ Gelir düzeyi } & Kötü / Orta & $32(0.64)$ & $33(0.66)$ & $0.044^{* * *}$ & 0.834 \\
\hline & İyi & $18(0.36)$ & $17(0.34)$ & & \\
\hline \multirow{4}{*}{ Yaşadığı yer } & Köy & $11(0.22)$ & $19(0.38)$ & & \\
\hline & Kasaba & $16(0.32)$ & $17(0.34)$ & $4.353^{* * *}$ & 0.113 \\
\hline & İl Merkezi & $23(0.46)$ & $14(0.28)$ & & \\
\hline & Yarım saatten sonra & $17(0.34)$ & $22(0.44)$ & & \\
\hline
\end{tabular}

*Student t-test, **Mann Whitney U Testi, ***Ki-kare $\left(\mathrm{x}^{2}\right)$ test.

\section{Kadınların Șimdiki Doğumuna İlișkin Özellikleri}

Kadınların şimdiki doğumuna ilișkin özellikleri incelendiğinde, grupların gebelik haftası, vital bulguları, $\mathrm{SPO}_{2}$ değerleri, doğum sonunda kullanılan vajinal ped sayısı, yenidoğanın 5. dk Apgar skoru ve kord pH'1, ağrı şiddeti, epizyotomi varlı̆̆1, emzirmeye başlama süresi, doğum memnuniyeti ve doğum sonu konforu arasında anlamlı bir farklılık bulunmamıştır ( $\mathrm{p}>0.05$; Tablo 2).

Kadınların Epizyotomi Varlığına ve İlk Emzirme Zamanına Göre Doğum Memnuniyeti ve Doğum Sonu

\section{Konforu}

Deney grubunda epizyotomi yapılmayan kadınların doğum sonu konfor ve memnuniyet puanları anlamlı düzeyde daha yüksek bulunmuştur (sırasıyla $4.16 \pm 0.48$, $\mathrm{p}=0.017$;
$3.96 \pm 0.63, \mathrm{p}=0.046)$. Kontrol grubunda ise kadınların doğum sonu konfor ve memnuniyet puanlarını epizyotominin etkilemediği belirlenmiştir (sırasıyla $\mathrm{p}=0.880, \mathrm{p}=0.528$ ). Gruplar arasında epizyotomi varlığına göre doğum sonu konfor ve memnuniyet puanları arasında anlamlı bir farklilık bulunmamıştır ( $\mathrm{p}>0.05$; Tablo 3 ).

Deney grubunda ilk yarım saatte bebeğini emziren kadınların doğum memnuniyeti ve doğum sonu konfor puanları anlamlı düzeyde daha yüksek bulunmuştur (sırasıyla $3.75 \pm 0.60, \mathrm{p}=0.002 ; 3.97 \pm 0.42, \mathrm{p}=0.025$ ). Kontrol grubunda ise ilk yarım saatte bebeğini emziren kadınların doğum sonu konfor düzeyleri daha yüksektir (sırasiyla $3.95 \pm 0.58, \mathrm{p}=0.018)$. Gruplar arasında ilk emzirmeye başlama zamanına göre doğum sonu konfor ve memnuniyet puanları arasında anlamlı bir farklılık bulunmamıştır (p>0.05; Tablo 4). 
Tablo 2. Kadınların Şimdiki Doğumuna İlişkin Bazı Özellikleri.

\begin{tabular}{|c|c|c|c|c|c|}
\hline & & $\begin{array}{l}\text { Deney } \\
\overline{\mathrm{x}} \pm \mathrm{SS} / \mathrm{n}(\%)\end{array}$ & $\begin{array}{l}\text { Kontrol } \\
\overline{\mathrm{x}} \pm \mathrm{SS} / \mathrm{n}(\%)\end{array}$ & İstatistik & $\mathrm{p}$ \\
\hline \multirow[t]{2}{*}{ Gebelik haftası } & & $39.3 \pm 1.1$ & $38.7 \pm 5.6$ & $-0.825^{* *}$ & 0.409 \\
\hline & Sistol (mmHg) & $112.6 \pm 10.2$ & $108.8 \pm 9.8$ & $1.891^{*}$ & 0.062 \\
\hline \multirow{3}{*}{ Doğum öncesi vital bulgular } & Diastol (mmHg) & $67.4 \pm 6.9$ & $67.4 \pm 7.2$ & $0.000^{*}$ & 1.000 \\
\hline & Nabız (atım/dk) & $83.4 \pm 4.8$ & $83.3 \pm 6.0$ & $0.055^{*}$ & 0.956 \\
\hline & Vücut 1 sisı $\left({ }^{\circ} \mathrm{C}\right)$ & $36.6 \pm 0.3$ & $36.7 \pm 0.2$ & $-1.641^{*}$ & 0.104 \\
\hline $\mathrm{SPO}_{2}$ & & $97.4 \pm 1.1$ & $97.3 \pm 0.9$ & $0.490^{*}$ & 0.625 \\
\hline Ped sayısı & & $4.7 \pm 1.6$ & $5.0 \pm 2.2$ & $-0.769^{*}$ & 0.444 \\
\hline 5. dk Apgar skoru & & $8.9 \pm 0.2$ & $8.9 \pm 0.2$ & $-0.390^{* *}$ & 0.697 \\
\hline Kord Ph'1 & & $7.4 \pm 0.2$ & $7.4 \pm 0.4$ & $-0.912^{* *}$ & 0.362 \\
\hline \multirow{2}{*}{ Ağrı şiddeti } & Hafif /orta & $18(0.36)$ & $13(0.26)$ & $1.169^{* * *}$ & 0.280 \\
\hline & Şiddetli & $32(0.64)$ & $37(0.74)$ & & \\
\hline \multirow{2}{*}{ Epizyotomi } & Var & $41(0.82)$ & $41(0.82)$ & $0.000 * * *$ & 1.000 \\
\hline & Yok & $9(0.18)$ & $9(0.82)$ & & \\
\hline \multirow[t]{2}{*}{ Emzirmeye başlama süresi } & İlk yarım saat içinde & $33(0.66)$ & $28(0.56)$ & $1.051 * * *$ & 0.305 \\
\hline & Yarım saatten sonra & $17(0.34)$ & $22(0.44)$ & & \\
\hline Doğum Memnuniyeti Ölçeği & & $3.5 \pm 0.6$ & $3.4 \pm 0.5$ & $1.102^{*}$ & 0.273 \\
\hline Doğum Sonu Konfor Ölçeği & & $3.8 \pm 0.4$ & $3.7 \pm 0.6$ & $1.004 *$ & 0.318 \\
\hline
\end{tabular}

*Student t-test, **Mann Whitney U Testi, ***Ki-kare $\left(\mathrm{x}^{2}\right)$ test.

Tablo 3. Grup İçinde ve Gruplar Arasında Epizyotomi Varlığına Göre Ölçek Puanlarının Karşılaştııılması.

\begin{tabular}{|c|c|c|c|c|c|c|c|c|c|c|c|c|c|c|c|}
\hline Grup & Ölçek & Epizyotomi & $\mathrm{n}$ & $\overline{\mathrm{x}}$ & SS & İstatistik* & $\mathrm{p}$ & Epizyotomi & Ölçek & Grup & $\mathrm{n}$ & $\overline{\mathrm{x}}$ & SS & İstatistik* & $\mathrm{p}$ \\
\hline \multirow{4}{*}{ Deney } & DMÖ & Var & 41 & 3.46 & 0.61 & -1.996 & 0.046 & & DMÖ & Deney & 41 & 3.46 & 0.61 & \multirow[t]{2}{*}{-0.302} & \multirow[t]{2}{*}{0.763} \\
\hline & \multirow{3}{*}{ DSKÖ } & Yok & 9 & 3.96 & 0.63 & & & Var & & Kontrol & 41 & 3.40 & 0.52 & & \\
\hline & & Var & 41 & 3.82 & 0.39 & -2.388 & 0.017 & & DSKÖ & Deney & 41 & 3.82 & 0.39 & \multirow[t]{2}{*}{-0.362} & \multirow[t]{2}{*}{0.717} \\
\hline & & Yok & 9 & 4.16 & 0.48 & & & & & Kontrol & 41 & 3.77 & 0.59 & & \\
\hline \multirow{4}{*}{ Kontrol } & DMÖ & Var & 41 & 3.40 & 0.52 & -0.632 & 0.528 & & DMÖ & Deney & 9 & 3.96 & 0.63 & \multirow[t]{2}{*}{-1.458} & \multirow[t]{2}{*}{0.145} \\
\hline & \multirow{3}{*}{ DSKÖ } & Yok & 9 & 3.52 & 0.54 & & & Yok & & Kontrol & 9 & 3.52 & 0.54 & & \\
\hline & & Var & 41 & 3.77 & 0.59 & -0.152 & 0.880 & & DSKÖ & Deney & 9 & 4.16 & 0.48 & \multirow[t]{2}{*}{-0.796} & \multirow[t]{2}{*}{0.426} \\
\hline & & Yok & 9 & 3.79 & 0.80 & & & & & Kontrol & 9 & 3.79 & 0.80 & & \\
\hline
\end{tabular}

Tablo 4. Grup İçinde ve Gruplar Arasında İlk Emzirme Zamanına Göre Ölçek Puanlarının Karşılaştırılması.

\begin{tabular}{|c|c|c|c|c|c|c|c|c|c|c|c|c|c|c|c|}
\hline Grup & Ölçek & $\begin{array}{c}\text { Emzirme } \\
\text { zamanı }\end{array}$ & $\mathrm{n}$ & $\overline{\mathrm{x}}$ & SS & $\begin{array}{l}\text { İstatis- } \\
\text { tik* }\end{array}$ & $\mathrm{p}$ & $\begin{array}{l}\text { Emzirme } \\
\text { zamanı }\end{array}$ & Ölçek & Grup & $\mathrm{n}$ & $\overline{\mathrm{x}}$ & SS & $\begin{array}{l}\text { İstatis- } \\
\text { tik* }\end{array}$ & $\mathrm{p}$ \\
\hline \multirow[t]{4}{*}{ Deney } & \multirow[t]{2}{*}{ DMÖ } & $\begin{array}{l}\text { İlk yarım } \\
\text { saat içinde }\end{array}$ & 33 & 3.75 & 0.60 & \multirow[t]{2}{*}{-3.042} & \multirow[t]{2}{*}{0.002} & \multirow{4}{*}{$\begin{array}{l}\text { Ilk yarım } \\
\text { saat içinde }\end{array}$} & \multirow[t]{2}{*}{ DMÖ } & Deney & 33 & 3.75 & 0.60 & \multirow[t]{2}{*}{-1.571} & \multirow[t]{2}{*}{0.116} \\
\hline & & $\begin{array}{l}\text { Yarım } \\
\text { saatten sonra }\end{array}$ & 17 & 3.17 & 0.55 & & & & & Kontrol & 28 & 3.51 & 0.48 & & \\
\hline & DSKÖ & $\begin{array}{l}\text { İlk yarım } \\
\text { saat içinde }\end{array}$ & 33 & 3.97 & 0.42 & -2.234 & 0.025 & & \multirow[t]{2}{*}{ DSKÖ } & Deney & 33 & 3.97 & 0.42 & \multirow[t]{2}{*}{-0.152} & \multirow[t]{2}{*}{0.879} \\
\hline & & $\begin{array}{l}\text { Yarım } \\
\text { saatten sonra }\end{array}$ & 17 & 3.70 & 0.38 & & & & & Kontrol & 28 & 3.95 & 0.58 & & \\
\hline \multirow[t]{4}{*}{ Kontrol } & DMÖ & $\begin{array}{l}\text { İlk yarım } \\
\text { saat içinde }\end{array}$ & 28 & 3.51 & 0.48 & \multirow{2}{*}{-1.437} & \multirow[t]{2}{*}{0.151} & \multirow{4}{*}{$\begin{array}{l}\text { Yarım } \\
\text { saatten } \\
\text { sonra }\end{array}$} & \multirow[t]{2}{*}{ DMÖ } & Deney & 17 & 3.17 & 0.55 & \multirow[t]{2}{*}{-1.458} & \multirow[t]{2}{*}{0.145} \\
\hline & & $\begin{array}{l}\text { Yarım } \\
\text { saatten sonra }\end{array}$ & 22 & 3.31 & 0.56 & & & & & Kontrol & 22 & 3.31 & 0.56 & & \\
\hline & DSKÖ & $\begin{array}{l}\text { İlk yarım } \\
\text { saat içinde }\end{array}$ & 28 & 3.95 & 0.58 & \multirow{2}{*}{-2.366} & \multirow{2}{*}{0.018} & & \multirow[t]{2}{*}{ DSKÖ } & Deney & 17 & 3.70 & 0.38 & \multirow[t]{2}{*}{-1.190} & \multirow[t]{2}{*}{0.234} \\
\hline & & $\begin{array}{l}\text { Yarım } \\
\text { saatten sonra }\end{array}$ & 22 & 3.55 & 0.62 & & & & & Kontrol & 22 & 3.55 & 0.62 & & \\
\hline
\end{tabular}

Not: Tüm puanların aritmetik ortalaması alınmıştır, *Mann-Whitney U testi, DMÖ: Doğum Memnuniyet Ölçeği, DSKÖ: Doğum Sonu Konfor Ölçeği. 


\section{TARTIŞMA}

Popülaritesi giderek artan doğumda hidroterapi kullanımı, doğum ağrısının azaltılması ve doğum konforunun arttırı1ması için kullanılmaktadır. ${ }^{5}$ Doğum eyleminde hidroterapi kullanımının, mortalite ve morbiditede artışa neden olmadığı, aksine indüksiyon ve epizyotomi gereksinimini azalttığı, hatta potansiyel maternal ve neonatal riskleri önlediği saptanmıştır. ${ }^{16}$ Travayda duş almanın doğum ve doğum sonrası konfora etkisini araştırmayı amaçladığımız bu çaıı̧̧mada, kadınların neredeyse yarısının ortaöğretim mezunu ve çoğunluğunun sosyoekonomik düzeyinin kötü/orta düzeyde olduğu ve çalışmadığı belirlenmiştir. Kadının Statüsü Genel Müdürlüğü (2020) verileri incelendiğinde, neredeyse her üç kadından birinin (\%29.4) istihdam edildiği ve çalışmamızdaki oranın Türkiye genelinden daha düşük olduğu görülmektedir. ${ }^{17}$

Doğum her kadın için benzersiz bir yaşam deneyimidir. Doğumda uterus kontraksiyonlarının neden olduğu ağrı, her kadın tarafindan farklı düzeyde hissedilen, fizyolojik, psikolojik ve çevresel faktörlerden etkilenen bir süreçtir. ${ }^{18}$ Çalışmamızda her iki grupta da kadınların çoğunluğu doğum esnasında şiddetli ağrı yaşadığını bildirmiştir. Yapılan analizlerde grupların ağrı skorları ve yaşanan ağrı şiddetine göre doğum memnuniyeti ve doğum sonu konforu puanlarında anlamlı bir fark bulunamamıştır. Floris ve arkadaşlarının (2017) çalışmalarında, doğum sürecinde yaşanan ağrının memnuniyet düzeyini etkilemediği belirlenmiştir. ${ }^{19}$ Kültürel olarak doğumda ağrı yaşanmasının kadınlar tarafından normal bir süreç olarak kabul edilmesi ile ilişkilendirmek mümkündür. Nitekim kadınların doğuma bakışının incelendiği bir çalışmada, kadınlar doğumda ağrı çekmenin annelik duygularını daha iyi hissetmeyi sağladığını, ağrı yaşamadan anne olunamayacağını düşündüklerini ifade etmişlerdir. ${ }^{20}$ Diğer yandan, doğum eyleminde nonfarmakolojik ağrı kontrolü uygulanılan gebelerde, farmakolojik yöntemlere daha az ihtiyaç duyulduğu ve doğum eyleminin epidural analjezi kullanan gebelere göre daha kısa sürede gerçekleştiği bildirilmiştir. ${ }^{9,21} \mathrm{Bu}$ gibi yararlarından dolayı, Vanderlaan'ın çalışmasındaki gebeler hidroterapiyi analjezi kullanımına tercih etmiştir. ${ }^{22}$ Tayvan'da yapılan bir çalışmada, doğumun ilk evresinde 11 k duş alan gebelerin ağrı skorlarının daha düşük ve doğum deneyimlerinin daha olumlu olduğu bildirilmiştir. ${ }^{23}$ Yine
Mısır'da yapılan bir çalışmada, doğumda duş aldırılan deney grubunun ağrı ve kaygı düzeyleri anlamlı derecede düşük bulunmuştur. ${ }^{24}$ Tuncay ve ark. (2019) çalışmasında, doğumun birinci evresinde hidroterapi uygulanan deney grubunda doğumun aktif fazının süresinin kısaldığı, ağrı düzeyinin azaldığı, doğum memnuniyetinin ve olumlu doğum deneyiminin arttığ rapor edilmiştir. ${ }^{10}$

Günümüzde doğum eyleminde gebeler genellikle sırt üstü veya yarı yatar pozisyonlar verilerek pasif hale getirilmektedir. Hâlbuki uterusun vena cava inferiyora bası yapmasını engelleyen, kadının hareketlerini kısıtlanmayan, pelvisin hareketli olduğu ve yerçekiminden yararlanılan dikey pozisyonların doğumda kullanılması önerilmektedir. ${ }^{25} \mathrm{Ça}$ lışmamızda doğum öncesinde gebelere hangi pozisyonda ağrıyı daha az hissettikleri sorulmuştur. Deney ve kontrol gruplarındaki gebelerin daha rahat olduklarını ifade ettikleri ayakta durma pozisyonu, aynı zamanda literatüre göre önerilen bir pozisyondur. ${ }^{26,27} \mathrm{Bu}$ anlamda fetüsün inişini kolaylaştıracak pozisyonlarda bulunmayı sağlayan duş uygulaması, doğum eyleminin konforunu olumlu yönde etkileyebilir. ${ }^{6}$

Doğum sürecinde bakımının odağı, yalnızca anne ve bebeğin güvende olması değil, anneye doğum sonu döneme uyumu için olumlu ve memnun edici bir doğum deneyimi yaşatmaktır. ${ }^{28}$ Doğum memnuniyeti, anne-yenidoğan sağlığ 1 için çok önemlidir. ${ }^{29}$ Çalışmamızda deney grubunda kadınların doğum memnuniyeti ve doğum sonu konforu arttıkça yenidoğanın sağlık göstergelerinin (5. dk Apgar skoru ve kord $\mathrm{pH}$ ) iyileştiği ve epizyotomi yapılmayan kadınların doğum sonu konfor ve memnuniyet puanlarının anlamlı düzeyde daha yüksek olduğu bulunmuştur. Ayrıca deney grubunda doğum sonu konfor ile doğum memnuniyeti arasında kuvvetli bir ilişki olduğu tespit edilmiştir. Bu sonuçlar, özellikle müdahalesiz doğumlarda travaydaki hidroterapi uygulamalarının, kadının doğum sonu konforunu ve doğum memnuniyetini arttırabileceğini göstermektedir. Elbette travayda yapılan gereksiz ve hoyratça yapılan müdahalelerin, doğum memnuniyetini ve konforunu olumsuz etkilemesi muhtemeldir. ${ }^{30}$ Bilindiği gibi, fizyolojik bir süreç olan doğum eyleminde herhangi bir sorun oluşmadığı sürece müdahale yapılması önerilmez. ${ }^{31} \mathrm{Kad}_{1}$ nın otonomisinin desteklendiği müdahalesiz doğumlarda, 
obstetrik sonuçların ve doğum memnuniyetinin dahaolumlu olduğu rapor edilmiştir. ${ }^{32}$ Bununla birlikte, Çıtak ve arkadaşlarının çalışmasında, doğuma ilişkin yapılan müdahalelerin doğum memnuniyetini etkilemediği belirlenmiştir. $^{33}$

Dünya Sağlık Örgütü'nün anne sütü ile emzirmeyi özendirmek, başlatmak ve desteklemek amacıyla "Bebek Dostu Hastaneler" ilkeleri kapsamında benimsediği “odanın paylaşımı" projesi, bebeğin anneden ayrılmasını gerektiren bir tıbbi gerekçe olmadığı sürece, yeni doğum yapmış kadınların bebekleriyle odalarına gelmelerinden itibaren taburcu olana kadar aynı odada kalmalarına dayanan bir hastane uygulamasıdır. ${ }^{34} \mathrm{Bu}$ anlamda aynı odada kalmak anne-bebek bağlanmasını, anne sütü miktarını ve doğum sonu konforu arttırmaktadır. ${ }^{35}$ Çalışmamızda deney grubunda ilk yarım saatte bebeğini emziren kadınların doğum sonu konfor ve doğum memnuniyeti düzeyleri; kontrol grubunda ise sadece doğum sonu konfor düzeyleri daha yüksek bulunmuştur. Moore ve arkadaşlarının postpartum kadınlar ve yenidoğan bebekleri ile yapılan 30 çalışmayı inceledikleri derlemelerinde, ten tene teması erken başlatılan bebeklerin vücut ısılarını daha iyi koruduğu, daha az ağladığı ve daha uzun süre emdiği bulunmuştur. ${ }^{36}$ Benzer şekilde, Ç1tak Bilgin ve ark. (2018) yaptığı çalışmada, doğum memnuniyeti ile ten tene temas arasında pozitif yönde ilişkili bulunmuştur. ${ }^{33} \mathrm{Bu}$ sonuçlar erken emzirmenin doğum sonu konforunu ve doğum memnuniyetini olumlu yönde etkileyebileceğini göstermektedir.

$\mathrm{Bu}$ çalışmanın en önemli sınırlılığı küçük bir örneklem üzerinde yapılmasıdır. Bu nedenle, çalışma sonuçları sadece bu örnekleme genellenebilir.

Çalışmamızda deney grubundaki kadınların doğum memnuniyeti ve doğum sonu konforu arttıkça yenidoğanın sağlık göstergelerinin iyileştiği belirlenmiştir. Travayda duş almanın doğum memnuniyeti ve doğum sonu konforu üzerine direk bir etkisi olmasa da, maternal ve neonatal sonuçlarını olumlu yönde etkileyebileceği belirlenmiştir. Gebelerin doğum memnuniyetini ve doğum sonu konforunu arttırmak için doğum ünitelerinde hidroterapi uygulaması yaygınlaştırılmalı ve sağlık personeli gebeyi duş alma konusunda desteklemelidir. Endikasyonu olmayan gebelere rutin epizyotomi gibi girişimler uygulanmamalıdır. Do- ğumda gebeye hareket özgürlüğü tanınarak dik pozisyonlara izin verilmelidir. Tıbbi bir gerekçe olmadığı sürece, anne ve bebek aynı odada kalmalı ve emzirme mümkün olduğunca erken başlatılmalıdır. Kadınların memnuniyet ve doğum sonu konfor düzeylerini arttıracak girişimler yaygınlaştırılmalıdır.

\section{Çıkar Beyannamesi}

Yazarlar, herhangi bir çıkar çatışmasının olmadığını beyan etmektedirler.

\section{Araştırmacıların Katkı Oranı Beyanı}

Ana fikir/Planlama: ST, ATO. Veri toplama/İşleme: ST. Veri analizi ve yorumlama: ATO. Literatür taraması: ST, ATO. Yazım: ST. Gözden geçirme ve düzeltme: ST, ATO. Danışmanlık: ATO.

\section{KAYNAKÇA}

1. Siefert ML. Concept Analysis of Comfort. Nurs Forum. 2002;37(4):16-23.

2. Kolcaba KY. A taxonomic structure for the concept comfort. Image J Nurs Scholarsh. 1991;23(4):237240 .

3. Kolcaba K. Comfort Theory and Practice: A Vision for Holistic Health Care and Research. New York: Springer Pub. Co; 2003.

4. Akgün Ö, Duran Aksoy Ö. Determination of mothers' postpartum comfort levels and affecting factors. Journal of Contemporary Medicine. 2020;10(3):385-393.

5. Karabulutlu Ö. Doğum Ağrısı Kontrolünde Kullanılan Nonfarmakolojik Yöntemler. Cauc J Sci 2014;1(1):43-50.

6. Uzunlar Ö, Özel S, Tokmak A, Üstün YE. Alternatif Bir doğum yöntemi; faydaları ve riskleri ile suda doğum. Jinekoloji - Obstet ve Neonatoloji Tıp Derg. 2017;14(4):187-191.

7. Toker E, Ovalı İ. Suda doğum. Türkiye Klin DoğumKadın Sağlığı ve Hast Hemşireliği - Özel Konular. 2015;1(3):87-95.

8. Shaw-Battista J. Systematic review of hydrotherapy research: Does a Warm Bath in Labor Promote Normal Physiologic Childbirth?. J Perinat Neonatal Nurs.2017;31(4):303-316.

9. Mollamahmutoğlu L, Moraloğlu Ö, Özyer Ş, et al. The effects of immersion in water on labor, birth and newborn and comparison with epidural analgesia and conventional vaginal delivery. J Turkish-German Gynecol Assoc. 2012;(13):45-49.

10. Tuncay S, Kaplan S, Moraloğlu Tekin Ö. An assessment of the effects of hydrotherapy during the active phase of labor on the labor process and parenting behavior. Clin Nurs Res. 2019;28(3):298-320.

11. Cohen J. Statistical Power Analysis for the Behavioral Sciences. 2nd ed. New York: Lawrence Erlbaum Associates; 1988.

12. Karakaplan S, Yildiz H. Doğum Sonu Konfor Ölçeği geliştirme çalışması. Maltepe Üniversitesi Hemşirelik Bilim ve Sanatı Derg. 2010;3(1):55-65.

13. Martin CH, Fleming V. The Birth Satisfaction Scale. Int J Health Care Qual Assur. 2011;24(2):124-135. 
14. Cetin F, Sezer A, Merih Y. The Birth Satisfaction Scale: Turkish adaptation, validation and reliability study. North Clin Istanbul. 2015;2(2):142-150.

15. IBM. SPSS Yazılımları - Türkiye. https://www.ibm.com/tr-tr/analytics/spss-statisticssoftware. Erişim tarihi 8 Şubat, 2021

16. Nutter E, Meyer S, Shaw-Battista J, Marowitz A. Waterbirth: an integrative analysis of peer-reviewed literature. J Midwifery Women's Health. 2014;59(3):286-319.

17. Kadının Statüsü Genel Müdürlüğü. Türkiye'de Kadın 2020 . https://www.ailevecalisma.gov.tr/media/38419/02-03-2020-tr-de-kadin.pdf. Erişim tarihi 3 Kasım, 2020.

18. Taşkın L. Doğum ve Kadın Sağlığı Hemşireliği. 13. Baskı. Ankara: Baskı Özyurt Matbaacılık; 2016.

19. Floris L, Irion O, Courvoisier D. Influence of obstetrical events on satisfaction and anxiety during childbirth: a prospective longitudinal study. Psychol Heal Med. 2017;22(8):969-977.

20. Duran Taşçı E, Atan Ünsal Ș. Kadınların sezaryen/vajinal doğuma ilişkin bakış açılarının kalitatif analizi. Genel Tip Derg. 2011;21(3):83-88

21. Karaçam Z, Akyüz E. Doğum eyleminde verilen destekleyici bakım ve ebe / hemşirenin rolü. IÜFN Hem Derg. 2011;19(1):45-53.

22. Vanderlaan J. Retrospective cohort study of hydrotherapy in labor. J Obstet Gynecol Neonatal Nurs. 2017;46(3):403-410.

23. Lee SL, Liu CY, Lu YY, Gau ML. Efficacy of warm showers on labor pain and birth experiences during the first labor stage. J Obstet Gynecol Neonatal Nurs. 2013;42(1):19-28.

24. Romia FAA, Adham AFME. Effect of warm showering on labor pain during the first stage of labor. Int $\mathrm{J}$ Adv Res. 2014;2(5):438-442.

25. Serçekuş P, İsbir GG. Investigation of active birth method with evidence based practice. TAF Prev Med Bull. 2012;11(1):97-102.

26. NICE. Intrapartum care of healthy women and babies. https://www.nice.org.uk/guidance/cg190. Erişim tarihi 3 Kasım, 2020.
27. The Royal College of Midwives. Evidence-based guidelines-Birthenvironment. https://www.rcm.org.uk/publicaons/?page=21\&memberfilter=false. Erișim tarihi 3 Kasım.2020.

28. Handelzalts JE, Becker G, Ahren M-P, et al. Personality, fear of childbirth and birth outcomes in nulliparous women. Arch Gynecol Obstet. 2015;291(5):10551062 .

29. Conesa Ferrer M, Canteras Jordana M, Ballesteros Meseguer C, Carrillo García C, Martínez Roche ME. Comparative study analysing women's childbirth satisfaction and obstetric outcomes across two different models of maternity care. BMJ Open. 2016;6(8):e011362.

30. Gungor I, Beji NK. Development and psychometric testing of the scales for measuring maternal satisfaction in normal and casarean birth. Midwifery. 2012;28(3):348-357.

31. Öztürk S, Kılıç M, Ağapınar Şahin S, Yıldız E. Women's knowledge about natural birth. Int Ref J Gynaecol Dis Matern Child Heal. 2016;(8):17-17.

32. Özcan Ş, Aslan E. Normal doğumda ve sezaryen doğumda anne memnuniyetinin belirlenmesi. Florence Nightingale Hemşirelik Derg. 2015;23(1):41.

33. Çıtak Bilgin N, Ak B, Coşkuner Potur D, Ayhan F. Doğum yapan kadınların doğumdan memnuniyeti ve etkileyen faktörler. Sağlık Bilim ve Meslekleri Derg. 2018;5(3):342-353.

34. World Health Organization. Evidence for the Ten Steps to Successful Breastfeeding. https://www.who.int/nutrition/publications/evidence_ten_step_eng.pdf Erişim tarihi 3 Kasım, 2020.

35. Cinar N, Sözeri C, Dede C, Cevahir R. Anne ve bebeğin aynı odada uyumasının emzirmeye etkisi. Maltepe Üniversitesi Hemşirelik Bilim ve Sanat Derg. 2010;(Sempozyum Özel Sayıs1):235-241.

36. Moore ER, Anderson GC, Bergman N, Dowswell T. Early skin-to-skin contact for mothers and their healthy newborn infants. Cochrane database Syst Rev. 2012;5(5):CD003519. 